\title{
Ações do Enfermeiro Urgentista no combate à COVID-19
}

\author{
Urgentist Nurse Actions in the Fight Against COVID-19 \\ Acciones Urgentista de Enfermeras en la lucha contra COVID-19
}

Recebido: 06/05/2021 | Revisado: 11/05/2021 | Aceito: 15/05/2021 | Publicado: 04/06/2021

\author{
Elane de Sousa Maciel Castro \\ ORCID: https://orcid.org/0000-0001-8576-8649 \\ Centro Universitário Santo Agostinho, Brasi \\ E-mail: ellenmaciel2010@ hotmail.com \\ Francisco das Chagas Silva de Oliveira \\ ORCID: https://orcid.org/0000-0002-4512-8513 \\ Centro Universitário Santo Agostinho, Brasil \\ E-mail: chagasfy@gmail.com \\ Magda Rogéria Pereira Viana \\ ORCID: https://orcid.org/0000-0003-3293-7095 \\ Centro Universitário Santo Agostinho, Brasil \\ E-mail: magdarogeria@hotmail.com
}

\begin{abstract}
Resumo
A COVID-19 é uma doença causada pela mutação do vírus SARS-COV2, que trouxe para saúde mundial um dos desafios mais laboriosos da história, o ano de 2020 está sendo marcado como a maior pandemia do século XXI, uma vez que a nova doença tem aspectos ainda desconhecidos, se tornando um desafio para os profissionais que atuam na linha de frente, especialmente a Enfermagem. Caracterizar as ações do Enfermeiro Urgentista no combate à COVID-19 evidenciadas na literatura e analisar a assistência do Enfermeiro Urgentista no Combate à COVID-19, de acordo com as publicações científicas. Trata-se de um estudo de revisão integrativa da literatura desenvolvida por meio da busca de publicações nas bases de dados Medline, BDENF, LILACS, IBECS, R. Multimídia, PAHO-IRIS, LIS e Coleciona SUS. O estudo evidenciou novas publicações acerca da assistência de enfermagem à COVID-19, demonstrando que estas ações estão em construção, o que reforça a necessidade estudos, principalmente relacionados as particularidades do vírus. Além disso, mostrou a importância do gerenciamento de enfermagem para construção do cuidado e os impactos na vida profissional do enfermeiro. Conclui-se que a assistência de enfermagem é fundamental para prestação de cuidados a pacientes com suspeita ou confirmação de COVID-19, necessitando de ampliação dos estudos, treinamentos e capacitação para aperfeiçoamento dos cuidados.
\end{abstract}

Palavras-chave: Assistência de enfermagem; Enfermagem; Covid-19; Pandemia; Enfermeira.

\begin{abstract}
The COVID-19 is a disease caused by the mutation of the SARS-COV2 virus, which brought to global health one of the most laborious challenges in history, the year 2020 is being marked as the greatest pandemic of the 21 st century, since the new disease there are still unknown aspects, becoming a challenge for professionals working in the front line, especially Nursing. To characterize the actions of the Urgent Nurse in the fight against COVID-19 evidenced in the literature and to analyze the assistance of the Urgent Nurse in the Fight against COVID-19, according to scientific publications This is an integrative review study of the literature developed through the search publications in the Medline, BDENF, LILACS, IBECS, R. Multimídia, PAHO-IRIS, LIS e Coleciona SUS. The study showed new publications about nursing care to COVID-19, demonstrating that these actions are under construction, which reinforces the need for studies, mainly related to the particularities of the virus. In addition, it showed the importance of nursing management for the construction of care and the impacts on the nurse's professional life. It is concluded that nursing care is essential to provide care to patients with suspected or confirmed COVID-19, requiring the expansion of studies, training and qualification to improve care.
\end{abstract}

Keywords: Nursing care; Nursing; Coronavirus; Pandemic; Nurse.

\section{Resumen}

COVID-19 es una enfermedad provocada por la mutación del virus SARS-COV2, que trajo a la salud mundial uno de los retos más laboriosos de la historia, el año 2020 se marca como la mayor pandemia del siglo XXI, desde la nueva enfermedad Aún quedan aspectos desconocidos, convirtiéndose en un desafío para los profesionales que trabajan en primera línea, especialmente Enfermería. Caracterizar las acciones del Enfermero de Urgencias en el combate al COVID19 evidenciadas en la literatura y analizar la asistencia del Enfermero de Urgencias en el Combate del COVID-19, según publicaciones científicas. Se trata de un estudio de revisión integradora de la literatura desarrollado mediante la búsqueda de publicaciones en las bases de datos Medline, BDENF, LILACS, IBECS, R. Multimídia, PAHO-IRIS, LIS y Coleciona 
SUS. El estudio mostró nuevas publicaciones sobre cuidados de enfermería al COVID-19, demostrando que estas acciones están en construcción, lo que refuerza la necesidad de estudios, principalmente relacionados con las particularidades del virus. Además, mostró la importancia de la gestión de enfermería para la construcción del cuidado y los impactos en la vida profesional del enfermero. Se concluye que el cuidado de enfermería es fundamental para brindar atención a los pacientes con COVID-19 sospechado o confirmado, requiriendo la ampliación de estudios, capacitación y calificación para mejorar la atención.

Palabras clave: Cuidado de enfermera; Enfermería; Coronavirus; Pandemia; Enfermero.

\section{Introdução}

O ano de 2020 trouxe para saúde mundial um dos desafios mais laboriosos da história, a pandemia da COVID-19, causada pela mutação de um patógeno, inicialmente denominado novo Coronavírus, conhecido dos pesquisadores desde 1937, e recebeu o nome científico de SARS-coV-2, sendo identificado pela primeira vez em dezembro de 2019 na cidade de Wuhan, província de Hubei, China, em um mercado de frutos do mar, causando a $1^{\circ}$ morte em 09 de janeiro de 2020 (Martins et al., 2020a).

Segundo dados da Organização Mundial da Saúde (OMS) e Organização Pan-Americana da Saúde (OPAS) após seu surgimento nas cidades chinesas, o Coronavírus espalhou-se pelo mundo e tornou-se uma das maiores pandemias da história, atingindo, até 18 setembro de 2020, 196 países, com 30.055.710 casos e 943.433 óbitos. Em comparação com outras doenças que causaram surtos em grande escala como a Síndrome Respiratória Aguda Grave (SARS), em 2002, atingiu 29 países com índice de fatalidade de 9,6\%, a Síndrome Respiratória do Oriente Médio (MERS) em 2012, atingiu 28 países com índice de fatalidade de 4,5\%, e o vírus Ebola, no ano de 1976, atingiu 9 países, com índice de fatalidade de 40,4\%, já o SARS-CoV2 em 2020 tem uma taxa de mortalidade em torno de 3,1\%, porém com número de países superior (OPAS, 2020).

Para Mallapaty (2020), as causas da doença ainda são inconclusivas, porém foram observados que indivíduos com comorbidades e senescência estão mais propensos a desenvolverem sintomas mais severos da doença, além da variabilidade de mutação do vírus. Atualmente, condições como hipertensão arterial sistêmica, Diabetes mellitus, condições neurológicas, pneumonias crônicas e demais doenças respiratórias estão sendo referenciadas como fatores agravantes na piora do quadro clínico dos pacientes (Borges et al., 2020).

No Brasil, o primeiro caso da doença foi registrado em 26 de fevereiro de 2020, segundo o Ministério da Saúde (MS). A partir disto, o país passou a adotar medidas de proteção para o combate à doença, utilizando os meios de comunicação para informar a população as particularidades da nova doença, prestando informações sobre a transmissão, fortalecendo a vigilância e a atenção à saúde e ampliando a cobertura do Sistema Único de Saúde (SUS), aos trabalhadores da saúde, considerados como prioritários nesta luta, por meio de protocolos da Agência de Vigilância Sanitária (Bellei \& Melchior, 2011).

No estado do Piauí, as autoridades de saúde adotaram medidas restritivas ante o surgimento dos primeiros casos, como distanciamento social, isolamento parcial e políticas de educação em saúde, como o uso de máscaras e higienização das mãos em ambientes de grande circulação, como forma de preparar o sistema público de saúde para o enfrentamento da doença. Em menos de um mês do primeiro caso confirmado no Brasil, no dia 19 de março de 2020, foi registrado o primeiro caso da doença no estado, e no dia 27 de março de 2020, registrou-se a primeira morte ocasionada pelo vírus na capital do Piauí/Teresina, segundo dados do boletim da Secretaria Estadual de Saúde do Piauí (SESAPI, 2020).

Segundo Trettel (2020), o novo Coronavirus encontrou um sistema de saúde em desgaste no Brasil, justificado pelas disparidades regionais, primordialmente econômicas e redimensionamento de profissionais da saúde. Neste cenário, os desafios preexistentes somaram-se ao pouco conhecimento sobre a doença e impuseram aos profissionais de saúde uma nova luta contra um inimigo invisível (Clementino, 2020). Esta nova realidade social impôs globalmente atitudes, antes praticadas por profissionais de saúde em pleno exercício da profissão, bem como outros que necessitassem delas para a prática do 
trabalho, como o uso de máscaras, hábitos de higiene, regras de distanciamento social e limpeza, que foram inseridos no dia a dia da população (Teixeira et al., 2020).

Nessa perspectiva, muitas atitudes precisaram ser adaptadas, outras modificadas, para aumentar a proteção para os profissionais de saúde e em especial o Enfermeiro, que comumente encontra-se na linha de frente do combate à COVID- 19, compondo as equipes nas unidades de saúde por todo país (Sousa e Souza, 2020). Estima-se que no Brasil tenha mais de 570 mil enfermeiros e enfermeiras, esse quantitativo animador se depara com realidades bastantes conflitantes, uma vez que o redimensionamento de profissionais, não engloba todas as regiões do país, acarretando sobrecarga em algumas cidades, principalmente em regiões afastadas dos grandes centros urbanos e que já se encontravam em dificuldades ante o período pandêmico (Silva \& Machado, 2020).

O ano de 2020 foi definido pela Organização Mundial da Saúde (OMS) como o Ano Internacional da Enfermagem, em comemoração aos 200 anos de aniversário do nascimento de Florence Nightingale, fundadora da enfermagem moderna, um ano marcado por homenagens e discussão de melhorias para a profissão. Em mais um desafio, a Enfermagem enfrenta a pandemia da COVID-19, procurando adaptar os processos de trabalho com a realidade, mudanças abruptas nos procedimentos operacionais, nas normas e rotinas, além da limitação no dimensionamento da equipe, reorganizar os serviços, os fluxos de atendimentos, ao mesmo tempo em que estão se atualizando quanto aos novos equipamentos e modalidades de assistência, tem como dever avaliar e monitorar em tempo real as pessoas acometidas pela COVID-19, contudo tem submetido o profissional a situações limites (UNIT, 2020).

O Enfermeiro encontra-se na linha de frente dos atendimentos aos casos de COVID-19, permanecem diariamente cuidando de pacientes, prestando assistências em diversos níveis e âmbitos hospitalares. Nesse sentido, o profissional encontrase em ambientes com potencial risco de transmissão, necessitando de segurança para execução dos cuidados. Uma vez que a pandemia possui inúmeras incógnitas que desafiam todos os profissionais da saúde, especialmente pelas novas condutas que se aperfeiçoam diariamente no manejo clinico da doença e particularidades dos pacientes (Alves \& Ferreira, 2020).

Diante do exposto, o estudo tem como objeto as ações do Enfermeiro Urgentista no combate à COVID-19, com a questão de revisão: Qual assistência do Enfermeiro Urgentista no combate à COVID-19 evidenciadas nas publicações cientificas? Para responder à questão foram levantados os objetivos: Caracterizar as ações do Enfermeiro Urgentista no combate à COVID-19 evidenciadas na literatura e analisar a assistência do Enfermeiro Urgentista no Combate à COVID-19, de acordo com as publicações científicas.

\section{Metodologia}

Trata-se de um estudo de revisão integrativa da literatura, que consiste em incluir a análise de pesquisas importantes, que dão sustentação para a tomada de definição e o desenvolvimento da atividade clínica, permitindo a concentração do modo da educação de uma definida questão, além de determinar ausências do conhecimento que necessitam ser preenchidas com a produção de novas pesquisas (Neves et al., 2017).

Foi utilizada a abordagem PICO, conforme o quadro 1, para desenvolvimento da questão de revisão e critérios de inclusão (População, Intervenção, Controle e Resultados), usada para elaboração de estudos não clínicos. Esses acrônimos podem ser usados para desenvolvimento de questões de variadas, possibilitando a definição correta de que informações são necessárias para a resolutividade da questão de pesquisa, além de maximizar a recuperação de evidências nas diversas bases de dados, foca o escopo da pesquisa e evita a realização de buscas desnecessárias (Lockwood et al., 2017). 
Quadro 1. Descritores de assuntos empregados nas buscas das publicações. Teresina/ PI, 2021

\begin{tabular}{|c|c|}
\hline \multicolumn{2}{|c|}{ Estratégia PICO } \\
\hline P & Profissionais Enfermeiros (as) \\
\hline $\mathbf{I}$ & Ações do Enfermeiro \\
\hline $\mathbf{C}$ & Não se aplica \\
\hline $\mathbf{O}$ & Ações do Enfermeiro Urgentista \\
\hline
\end{tabular}

Fonte: BVS.

Para a construção de uma revisão integrativa é necessário seguir seis etapas distintas: a identificação do tema e seleção da hipótese ou questão de pesquisa; estabelecimento de critérios para inclusão e exclusão de estudos/amostragem ou busca na literatura; definição das informações a serem extraídas dos estudos selecionados/ categorização dos estudos; avaliação dos estudos incluídos; interpretação dos resultados; e apresentação da revisão/síntese do conhecimento (Ercole et al., 2014).

O levantamento bibliográfico foi realizado por meio de publicações selecionadas nas bases de dados online: Sistema Online de Busca e Análise de Literatura Médica (MEDLINE), Literatura Latino-Americana e do Caribe em Ciências da Saúde (LILACS), Base de Dados de Enfermagem (BDENF), Índice Bibliográfico Español en Ciencias de la Salud (IBECS), Pan American Heath Organization- Institutional Repository for Information Sharing (PAHO-IRIS), Localizador de Informação em Saúde (LIS) e coleciona SUS, com os Descritores em Saúde (DeCS): assistência de enfermagem AND enfermagem AND coronavírus AND pandemia AND enfermeiro, suas correspondentes em inglês por meio da Medical SubjectHeadings (MeSH): AND Nursing Care AND Nursing AND Coronavirus AND Pandemic AND Nurse.

Nos critérios de inclusão foram selecionadas publicações que apresentaram textos completos, em português e inglês, no período de 2020 a 2021, que abordaram as ações do Enfermeiro Urgentista no combate à COVID-19. Como critérios de exclusão, foram descartados teses, dissertações, artigos de opinião, artigos pagos, publicações em jornais digitais e impressos que não apresentavam relação com a temática.

Os dados foram coletados por meio de um formulário (APÊNDICE A) contendo as seguintes variáveis: Autor e ano de publicação; Título do artigo; Objetivo; Tipo de estudo e evidências. Selecionadas as evidencias mostradas neste artigo (quadro 2), sumarizamos a revisão das publicações por meio do fluxograma (PRISMA) (Moher, et al., 2009). A discussão dos mesmos, aconteceu conforme as publicações estudadas.

\section{Resultados}

Com a estratégia de pesquisa foram capturadas 131 publicações científicas (figura 1). Posteriormente a esta etapa, foram removidas 14 publicações duplicadas, em seguida foram lidos os títulos e resumos, removendo 91 estudos, restando 26 para leitura e análise de textos completos. Em seguida, foram removidas publicações por apresentarem os seguintes motivos: outro idioma, não aborda a temática proposta e estudo na integra não disponível, reduzindo, assim, 19 artigos. Depois de realizada a leitura criteriosa dos artigos selecionados, para obtenção daqueles que possuíam relação com a temática, resultou-se em uma amostra final de 08 artigos (Figura 1).

A Figura 1- representa o processo de seleção da literatura cientifica, através do Fluxograma PRISMA. Teresina-PI, 2021. 
Fluxograma 1. Processo de seleção da literatura cientifica.
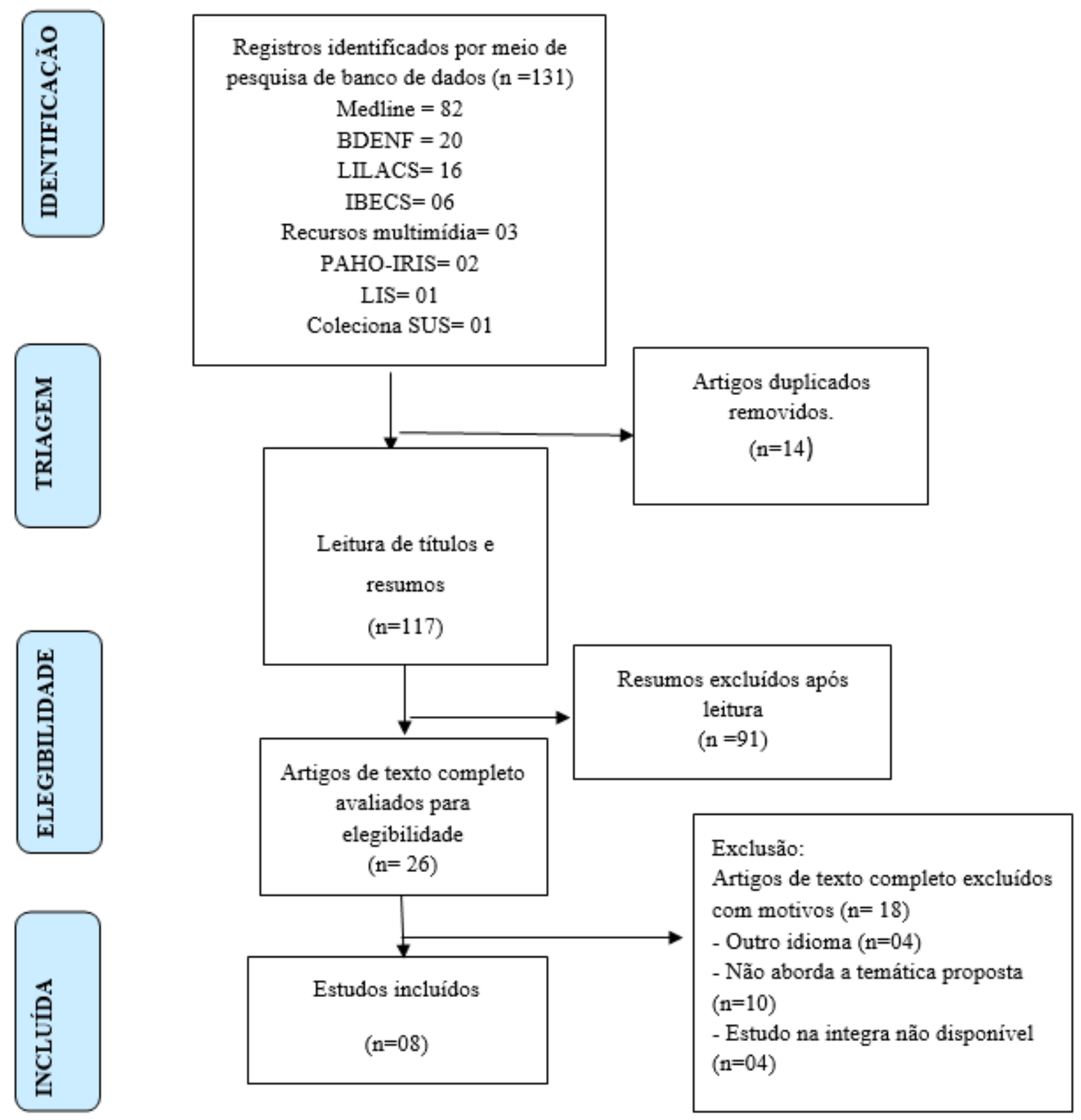

Fonte: BVS. 
Após a seleção dos artigos, os mesmos foram apresentados no quadro 2, de acordo com Autor e ano de publicação, Título do artigo, Objetivo, Tipo de estudo e Evidências.

Quadro 2: Representa as especificações de cada um dos artigos (08 artigos).

\begin{tabular}{|c|c|c|c|c|}
\hline $\begin{array}{c}\text { Autor e ano } \\
\text { de } \\
\text { publicação }\end{array}$ & Título do artigo & Objetivo & Tipo de estudo & Evidências \\
\hline $\begin{array}{c}\text { Bitencourt } e t \\
\text { al., } \\
\text { (2020). }\end{array}$ & $\begin{array}{l}\text { Protagonismo do } \\
\text { enfermeiro na } \\
\text { Estruturação e gestão } \\
\text { de uma Unidade } \\
\text { específica para covid- } \\
19 .\end{array}$ & $\begin{array}{l}\text { Relatar a experiência no processo } \\
\text { de estruturação e gestão de uma } \\
\text { unidade específica para COVID- } \\
\text { 19, ressaltando o protagonismo do } \\
\text { enfermeiro nas tomadas de } \\
\text { decisão. }\end{array}$ & $\begin{array}{l}\text { Relato } \\
\text { experiência }\end{array}$ & $\begin{array}{l}\text { O estudo destaca o protagonismo do } \\
\text { enfermeiro em todas as interfaces, desde a } \\
\text { participação na estruturação das comissões } \\
\text { até a assistência direita ao paciente com } \\
\text { COVID } 19 .\end{array}$ \\
\hline $\begin{array}{c}\text { Treccossi } e t \\
\text { al., } \\
\text { (2020). }\end{array}$ & 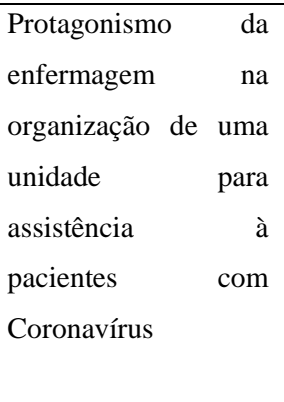 & $\begin{array}{l}\text { Relatar o protagonismo vivenciado } \\
\text { por líderes da enfermagem, na } \\
\text { organização de uma unidade de } \\
\text { internação hospitalar, destinada } \\
\text { exclusivamente aos pacientes com } \\
\text { infecção suspeita e confirmada por } \\
\text { Coronavírus. }\end{array}$ & $\begin{array}{l}\text { Relato } \\
\text { experiência }\end{array}$ & $\begin{array}{l}\text { A enfermagem participa de todas as etapas e } \\
\text { processos necessários à organização e } \\
\text { ativação da unidade de atendimento para } \\
\text { COVID-19, exercendo as seguintes } \\
\text { competências: comunicação; tomada de } \\
\text { decisão; liderança; administração e } \\
\text { gerenciamento; assistência à saúde; } \\
\text { educação permanente. }\end{array}$ \\
\hline $\begin{array}{l}\text { Chaves } \\
\text { et al., } \\
(2020) \text {. }\end{array}$ & $\begin{array}{ll}\text { Reflexões acerca } & \text { do } \\
\text { exercício } & \text { da } \\
\text { supervisão } & \text { de } \\
\text { enfermagem no } & \\
\text { Enfrentamento } & \text { da } \\
\text { covid-19 } & \end{array}$ & $\begin{array}{l}\text { Refletir teoricamente acerca de } \\
\text { contribuições da supervisão de } \\
\text { enfermagem no enfrentamento da } \\
\text { COVID-19. }\end{array}$ & Estudo reflexivo & $\begin{array}{l}\text { A supervisão de enfermagem mobiliza } \\
\text { conhecimentos e informações para } \\
\text { dimensionar recursos diversos e planejar } \\
\text { ações em educação continuada no combate } \\
\text { à COVID-19. }\end{array}$ \\
\hline $\begin{array}{l}\text { Ribeiro et } \\
\text { al., (2020). }\end{array}$ & $\begin{array}{l}\text { Ano internacional da } \\
\text { enfermagem: dos } 200 \\
\text { anos de } \\
\text { Nightingale } \\
\text { pandemia } \\
\text { COVID-19 }\end{array}$ & $\begin{array}{l}\text { Refletir sobre o } 200^{\circ} \text { aniversário } \\
\text { do nascimento de Florence } \\
\text { Nightingale e a pandemia pela } \\
\text { COVID-19, no Ano Internacional } \\
\text { da Enfermagem. }\end{array}$ & Teórico- reflexivo & $\begin{array}{l}\text { Importância do resgate dos principais } \\
\text { pressupostos de Florence Nightingale para } \\
\text { prevenção e tratamento de doenças. A } \\
\text { contribuição vital da enfermagem no } \\
\text { combate à COVID-19, valorizando o } \\
\text { empoderamento da enfermagem frente aos } \\
\text { desafios da pandemia. }\end{array}$ \\
\hline $\begin{array}{c}\text { Backes et al., } \\
\text { (2020). }\end{array}$ & $\begin{array}{l}\text { Novo coronavírus: o } \\
\text { que a enfermagem } \\
\text { tem a aprender e } \\
\text { ensinar em tempos de } \\
\text { pandemia? }\end{array}$ & $\begin{array}{l}\text { Promover uma análise teórico- } \\
\text { reflexiva sobre o que a } \\
\text { enfermagem tem a aprender e } \\
\text { ensinar à sociedade global em } \\
\text { tempos de pandemia da COVID- } \\
19 .\end{array}$ & $\begin{array}{l}\text { Ensaio teórico- } \\
\text { reflexivo }\end{array}$ & $\begin{array}{l}\text { A enfermagem promove a assistência nas } \\
\text { múltiplas dimensões que o paciente está } \\
\text { inserido, tais como física, emocional, } \\
\text { espiritual, familiar, social, política e } \\
\text { econômica. }\end{array}$ \\
\hline $\begin{array}{c}\text { Oliveira } e t \\
\text { al., } \\
(2021) .\end{array}$ & $\begin{array}{l}\text { Nursing Now e } \text { o } \\
\text { papel da enfermagem } \\
\text { no contexto } \\
\begin{array}{ll}\text { pandemia } \quad \text { e } & \text { do } \\
\text { trabalho atual. }\end{array}\end{array}$ & $\begin{array}{l}\text { Discutir sobre a } \text { Campanha } \\
\text { Nursing Now e o papel da } \\
\text { enfermagem em tempos de } \\
\text { pandemia por COVID- } 19 .\end{array}$ & $\begin{array}{l}\text { Reflexão teórica } \\
\text { baseada na } \\
\text { literatura cientifica. }\end{array}$ & $\begin{array}{l}\text { Na campanha Nursing Now, os profissionais } \\
\text { de enfermagem são valorizados, } \\
\text { especialmente no cenário da pandemia } \\
\text { COVID-19. A enfermagem lidera, possui } \\
\text { agir político, capacidade para dialogo, } \\
\text { responsabilidade social com pacientes e } \\
\text { profissionais de enfermagem. }\end{array}$ \\
\hline
\end{tabular}




\begin{tabular}{|c|c|c|c|c|}
\hline $\begin{array}{l}\text { Reis et al., } \\
\text { (2020). }\end{array}$ & $\begin{array}{l}\text { Atuação } \text { da } \\
\text { enfermagem no } \\
\text { cenário da pandemia } \\
\text { COVID-19 }\end{array}$ & $\begin{array}{l}\text { Relatar as experiências, receios e } \\
\text { anseios dos profissionais de } \\
\text { enfermagem que atuam na linha de } \\
\text { frente aos cuidados de pacientes } \\
\text { suspeitos e confirmado da } \\
\text { COVID-19. }\end{array}$ & $\begin{array}{l}\text { Estudo descritivo, } \\
\text { exploratório, com } \\
\text { abordagem } \\
\text { qualitativa, do tipo } \\
\text { relato de } \\
\text { experiência }\end{array}$ & $\begin{array}{l}\text { Os profissionais relatam insegurança e } \\
\text { medo do adoecimento para realização da } \\
\text { assistência aos pacientes com suspeita ou } \\
\text { confirmação de COVID-19. }\end{array}$ \\
\hline $\begin{array}{c}\text { Souza et al., } \\
(2020) .\end{array}$ & $\begin{array}{l}\text { Assistência de } \\
\text { enfermagem durante } \\
\text { a pandemia de covid- } \\
\text { 19: um relato de } \\
\text { experiência }\end{array}$ & $\begin{array}{l}\text { Descrever a experiência r na } \\
\text { assistência de } \\
\text { casos suspeitos ou confirmados de } \\
\text { COVID-19 }\end{array}$ & Artigo original & $\begin{array}{l}\text { Os profissionais relatam medo de } \\
\text { contaminação, transmissão a familiares e de } \\
\text { serem facilitadores da transmissão. }\end{array}$ \\
\hline
\end{tabular}

Fonte: BVS.

\section{Discussão}

A partir das evidências encontradas nas publicações do quadro 2, por similaridade de conteúdo, surgiram três categorias, a saber: Gerenciamento de Enfermagem no combate à COVID-19, Assistência de Enfermagem no combate à COVID-19 e Impactos da COVID-19 sobre a assistência de Enfermagem, posteriormente descritas a seguir.

\subsection{Categoria 1- Gerenciamento de Enfermagem no combate à COVID-19}

Segundo Bitencourt et al., (2020a) o enfermeiro é fundamental para garantia dos cuidados aos pacientes acometidos pela COVID-19, estes profissionais são atuantes, participando da elaboração do espaço físico hospitalar, este planejamento se dar pela separação de pacientes com suspeita ou confirmação de casos, garantindo segurança aos profissionais e pacientes das unidades.

Outro mecanismo utilizado é a SAE nos fluxos operacionais e clínicos, esta mostrou-se fundamental uma vez que tal estratégia auxilia no planejamento do cuidado, na criação das equipes de resposta rápida, estrutura de pontos de recepção para indivíduos com quadros respiratórios. Nisto, são elencadas ações de cuidado, dimensionamento de profissionais, treinamentos dos profissionais acerca de utilização e descarte de EPIS (Bitencourt et al.,2020b).

Em similaridade, Treccossi et al (2020a) diz que a liderança de enfermagem participa de todas as etapas, desde a organização a ativação da unidade hospitalar, por meio de pressupostos como a comunicação, tomada de decisões, liderança, administração e gerenciamento, além da assistência à saúde e educação em saúde. Nesse contexto, o enfermeiro reestrutura e reorganiza a rede hospitalar e dinâmica assistencial, procurando adequar as recomendações de órgãos da saúde aos conhecimentos da pratica laboral diária dos profissionais.

As competências gerenciais são importantes ao enfermeiro gestor, auxiliam na organização da assistência, na comunicação é um pressuposto fundamental, uma vez que visa obter respostas positivas das equipes no planejamento da assistência, assim, a abertura do diálogo, acessibilidade, confiabilidade e flexibilidade aproximam os profissionais da nova realidade pandêmica, readaptando experiências vivenciados em outras situações, com os implementados perante à COVID-19. A tomada de decisões é outro mecanismo fundamental, uma vez que garante o planejamento das medidas de contingência do enfrentamento da doença. a segurança dos profissionais, disponibilidade de leitos (Treccossi et al., 2020b).

$\mathrm{Na}$ liderança, pressuposto fundamental para desempenho da equipe de enfermagem, são escolhidos profissionais para atuarem na linha de frente, estes possuem qualificação técnica e competência gerencial, empatia, responsabilidade, comprometimento e habilidade de comunicação, procurando não ser arbitrário, mas construir com a equipe, profissionais líderes na organização do cuidado (Treccossi et al., 20020c). 
Como ciência, a enfermagem utiliza de conhecimentos para dimensionar recursos diversos e planejar ações de enfoque gerencial e de atenção à saúde, através dos pressupostos da supervisão. O trabalho da enfermagem é organizado mediante subprocessos, cuidar e assistir, administrar e gerenciar, pesquisar e ensinar, assim, cada processo planeja seus objetos, atividades, intercalado no mesmo momento e local. Nesse contexto, Enfermeiros, Técnicos e Auxiliares estão inseridos, de forma heterogênea e hierarquizada, com responsabilidade técnica e social expressadas para atividade laboral (Chaves et al.,2020a).

Segundo o decreto 94.406/87, é função privativa do Enfermeiro: planejamento, organização, coordenação, execução e avaliação dos serviços prestados pela assistência de enfermagem. Determinando assim, as práticas dos técnicos e auxiliares, só podem ser supervisionadas pelo Enfermeiro, através das orientações e direcionamentos (Chaves et al.,2020b).

\subsection{Categoria 2- Reflexos da COVID-19 sob a assistência do Enfermagem}

Para Oliveira et al., (2021) a Campanha Nursing Now e o papel da enfermagem em tempos de pandemia por COVID19, mostrou que a enfermagem possui temáticas que arrastam, seja no ensino, na prática ou na pesquisa. Somados a outros problemas da classe temos: luta diária por melhores condição de trabalho, EPIS adequados disponíveis em quantidade e qualidade suficiente, jornada de trabalho definida, dimensionamento adequado de profissionais, piso salarial e respeito perante a sociedade. Além de adicionais, como retirada dos direitos trabalhistas, violência e assédio moral de sexual, precaridade de formação e desgaste laboral.

Diante disso Reis et al., (2020a) relata em seu estudo as experiências, receios e anseios dos profissionais de enfermagem que atuam na linha de frente aos cuidados de pacientes suspeitos e confirmado da COVID-19. Nesse sentido, relatam insegurança, medo do adoecimento e transmissão a familiares, assim. prejudicando a assistência aos pacientes com suspeita ou confirmação de COVID-19.

Entretanto, os desafios enfrentados, demonstra uma enfermagem resiliente em todas as situações, procurando ofertar segurança na prestação do cuidado, mesmo diante de queixas recorrentes que dificultam o trabalho dos profissionais. No entanto, ao longo da pandemia, são inúmeras as manifestações de respeito pela população em todos os lugares do mundo, com aplausos em janelas e hospitais, diferentemente disso, os anseios da enfermagem não são atendidos pelos governantes, estes últimos, na piora da crise oferecem altos salários aos profissionais, nisso, alguns aceitam tais condições afim de melhores remunerações, o que em períodos ante pandemia, só era possível mediante plantões exaustivos em diversos centros de saúde (Reis et al., 2020b).

O estudo de Souza et al., (2020) descreve a experiência na assistência de enfermagem aos casos suspeitos ou confirmados de COVID-19. No tocante ao medo da contaminação, os profissionais tem considerável diminuição na qualidade da assistência, assim como, a possibilidade da transmissão a familiares e amigos, uma vez que estes profissionais possuem vivência familiar, diretamente em contato com pessoas que possuem comorbidades, por exemplo, obrigando muitos desses profissionais ao afastamento dos lares. Além disso, os profissionais são agredidos moralmente, mediante xingamentos ou provocações em ambientes públicos, muitas pessoas julgam a circulação desses profissionais no meio social, justificando que estes, trazem a doença do ambiente hospitalar para a população.

\subsection{Categoria 3- Assistência de Enfermagem no combate à COVID-19}

Ao longo dos 200 anos de história da enfermagem, os cuidados foram construídos de acordo com os episódios que a humanidade enfrenta ao longo de sua existência, ações que são conhecidas, orientações de educação em saúde e ambiência, as mesmas preconizadas por Florence Nightingale, que acreditava que o ambiente poderia garantir saúde ou doença, necessitando de orientações em saúde. Assim, no contexto da pandemia da COVID-19, orientações foram inseridas, outras adaptadas, como 
lavagem correta das mãos, uso do álcool em gel, distanciamento social em todos os ambientes, higienização de objetos e superfície e uso de mascaras, ampliando essas condutas através de informes e treinamentos (Ribeiro et al.,2020a).

É importante destacar que a execução do cuidado é fundamental para melhora do quadro dos pacientes acometidos por qualquer enfermidade, nesse caso à COVID-19, apresentam pacientes restrito ao leito hospitalar, sejam UTI ou enfermarias, sem qualquer contato físico com familiar, nesse cenário o enfermeiro busca atender a integralidade dos pacientes, física, emocional, espiritual, familiar, social, política e econômica (Backes et al., 2020a).

Nesse contexto, o Enfermeiro é uma linha de transmissão de informação entre familiares e pacientes, em grande maioria, além de informar, o profissional transmite manifestação de carinho e zelo, procurando diminuir as angustias dos pacientes e parentes (Backes et al.,2020b).

De acordo Ribeiro et al., (2020b) a necessidade de valorização dos profissionais de enfermagem é constante, objetivos da classe se arrastam desde os primórdios da enfermagem, em mais de 200 anos de história e precisam de aprovação. Neste contexto, o Enfermeiro se depara com situações delicadas, principalmente porque a COVID-19 possui inúmeros duvidas, assim, os profissionais planejam o cuidado conforme experiências antes executadas em outros momentos de crises, como guerras e endemias.

\section{Conclusão}

Esse estudo atendeu aos objetivos propostos e mostrou-se de grande relevância, contribuindo para o planejamento de ações do Enfermeiro Urgentista no combate à COVID-19, além de abrir caminhos para outros estudos, uma vez que, a temática é atual e há inúmeros questionamentos que precisam de respostas, assim, houve limitação relacionada a estudos sobre o tema.

Sugere-se a inclusão desse assunto durante o processo de formação do profissional de enfermagem, no sentido de prepará-lo para uma assistência qualificada, exigindo do mesmo conhecimento específico, baseado nas evidências que estão sendo construídas conforme adequação das ações do Enfermeiro mediante novos protocolos assistenciais.

Dessa forma, é relevante destacar que o papel do Enfermeiro na assistência ao paciente com suspeita ou confirmação de COVID-19, deve ser enfatizado, especialmente nos cursos de graduação, para que os acadêmicos tenham uma noção de como proceder na vivência profissional.

São necessários treinamento e capacitação contínua de profissionais da enfermagem que lidam com esse tipo de situação para que os mesmos tenham segurança e forneçam uma assistência eficaz e de qualidade, ofertando ao paciente um atendimento holístico para sua pronta recuperação.

A assistência do Enfermeiro Urgentista a pacientes com COVID-19 é essencial, uma vez que estes profissionais atuam diuturnamente prestando cuidado, conforme preconizados pelos protocolos assistências que estão sendo construídos. Neste contexto, são necessários mais estudos que abordem a temática, fomentando especialmente na organização dos protocolos assistenciais para futuros profissionais de enfermagem.

\section{Referências}

Assessoria de comunicação da SESSAPI. Boletim epidemiológico. Portal da saúde do governo do estado. http://www.saude.pi.gov.br/noticias/2020-0331/9634/governo-do-estado-apresenta boletim-epidemiologico-detalhado.html.

Alves, J. C. R. A., \& Ferreira, M. B. (2020). COVID-19: Reflexão da Atuação do Enfermeiro no Combate ao Desconhecido. Enferm. Foco. 11(1, especial), $74-7$

Backes, M. T. S., Carvalho, K. M., Santos, E. K. A., \& Backes, D. S. (2020). New coronavirus: what does nursing have to learn and teach in times of a pandemic? Rev Bras Enferm;73(Suppl 2):e20200259. http://dx.doi.org/10.1590/0034-7167-2020-0259

Bellei, N., \& Boim, M. T. H1N1: pandemia e perspectiva atual Jornal Brasileiro de Patologia e Medicina Laboratorial, vol. 47, núm. 6, diciembre, 2011, pp. 611-617 Sociedade Brasileira de Patologia Clínica/Medicina Laboratorial Rio de Janeiro, Brasil. 
Bitencourt, J. V. O. V., Meschial, W. C., Frizon, G., Biffi, P., Souza, J. B., \& Maestri, E. (2020). Nurse's protagonism in structuring and managing a specific unit for COVID-19. Texto Contexto Enferm [Internet][cited YEAR MONTH DAY]; 29:e20200213. https://doi.org/10.1590/1980-265X-TCE-2020-0213

Borges, K. N. G., Oliveira, R. C., Macedo, D. A. P., Santos, J. C, \& Pellizzer, L. G. M. (2020). O impacto da pandemia de COVID-19 em indivíduos com doenças crônicas e a sua correlação com o acesso a serviços de saúde. Rev Cient Esc Estadual Saúde Pública Goiás “Candido Santiago”. 6(3):e6000013

Clementino, F. S., Chaves, A. E. P., Pessoa, J. M., Miranda, F. A. N., Medeiros, S. M., \& Martiniano, C. S. (2020). Enfermagem na atenção às pessoas com COVID-19: desafios na atuação do sistema COFEN/CORENS. Texto Contexto Enferm 29: e20200251. https://doi.org/10.1590/1980-265X-TCE-2020-0251

Ercolle, F. F., Melo, L. S, \& Alcoforado, C. L. G. C. (2014) Revisão integrativa versus revisão sistemática. Revista Mineira de Enfermagem, 18(1), 9-12, http://www.dx.doi.org/10.5935/1415-2762.20140001

Jornada de Enfermagem debate a "Gestão e assistência da área no enfrentamento à COVID-19". Universidade Tiradentes. Sergipe, 9/05/2020 às 14h35 https://portal.unit.br/blog/noticias/jornada-de enfermagem-debate-a-gestao-e-assistencia-da-area-no-enfrentamento-a-covid 19.

Lockwood, C., et al. Chapter 2: Systematic reviews of qualitative evidence. In: Aromataris E, Munn Z (Editors). Joanna Briggs Institute Reviewer's Manual. The Joanna Briggs Institute, 2017

Mallapaty, S. Coronavirus can infect cats - dogs, not so much [published online ahead of print, 2020 Apr 1]. Nature. 2020; 10.1038/d41586-020-00984-8. $10.1038 / \mathrm{d} 41586-020-00984-8$

Martins, L. R., et al. Emergência do novo coronavírus (SARS-CoV-2) e o papel de uma vigilância nacional em saúde oportuna e efetiva. Cad. Saúde Pública, $36(3)$

Ministério da Saúde (BR). Secretaria de Atenção Primária à Saúde. Coronavírus COVID-19: protocolo de manejo clínico do Novo Coronavírus (COVID- 19 na Atenção Primária à Saúde. Brasília, DF: Ministério da Saúde.

Moher, D.; Liberati, A.; Tetzlaff, J., \& Altman, D. G. meta-Analyses: the PRISMA statement. BMJ. 1-8.

Neves et al. Revisão Integrativa: Conceitos e métodos para desenvolvimento. $17^{\circ}$ CONIC. SEMESP. Universidade Brasil, 2017.

Oliveira, K. K. D, Freitas, R. J. M, Araújo, J. L, \& Gomes, J. G. N. Nursing Now e o papel da enfermagem no contexto da pandemia e do trabalho atual. Rev Gaúcha Enferm. 42, e20200120. https://doi.org/10.1590/1983-1447.2021.20200120

Organização PAN- Americana da Saúde. (OPAS) Folha informativa COVID-19 - Escritório da OPAS e da OMS no Brasil. Brasil; 2020

Pandemia de doença por coronavírus (COVID-19) World Health Organization. https://www.who.int/.

Ribeiro, O. M. P. L, Fassarella, C. S, Trindade, L. L, et al. Ano internacional da/o enfermeira/o: dos 200 anos de Florence Nightingale à pandemia por Covid19. Revista de Enfermagem do Centro Oeste Mineiro 2020;10:e3725. http/doi.org/recom.v10i0.3725

Reis. M. L, Lago. N. P, Carvalho, S. A. H. S, Nobre, V. N. N, \& Guimarães, A. P. R, Atuação da enfermagem no cenário COVID-19. Ver. Nursing, 2020,23 (269): 4765.4768. https://doi.org/10.36489/nursing.2020v23i269p4765-4772

Silva, M. N., \& Machado, M. H. (2020). Sistema de saúde e trabalho: desafios para enfermagem no Brasil. Rev. Ciência \& Saúde coletiva, 20 de dezembro de 2019

Souza e Souza, L. P. S, \& Souza, A. G. Enfermagem brasileira na linha de frente contra o novo Coronavírus: quem cuidará de quem cuida? J. nurs. health. 2020;10:e20104005

Teixeira, C. P. S et al- A saúde dos profissionais de saúde no enfrentamento da pandemia de Covid- 19. Ciência \& Saúde Coletiva, 25(9):3465-3474, 2020.

Treccossi, S. P. C., Ferreira, J. C., Oliveira, R. M., Santos, R. P., \& Carvalho, A. R. S. (2020). Protagonismo da enfermagem na organização de uma unidade para assistência à pacientes com Coronavírus. J. nurs,health, 10(n.esp.):e20104039: https://periodicos.ufpel.edu.br/ojs2 /index.php/enfermage m/article/view/19859

Trettel, N. et al. Impacto da covid-19 sob o trabalho da enfermagem brasileira: aspectos epidemiológicos. Rev. Enfermagem em foco, 2020

Chaves, L. D. P., Fabro, G. C. R., Galiano C., Trovó, M. C., Tomaz, W. B, \& Gleriano, J. S. (2020) Reflexões acerca do exercício da supervisão de enfermagem no enfrentamento da COVID-19. Cuid Enferm. 14(1):10-17. 1118508 